\title{
PENGARUH RETURN ON EQUITY, EARNING PER SHARE, DAN DEBT TO EQUITY RATIO TERHADAP RETURN SAHAM (STUDI PADA EMITEN SAHAM SYARIAH SEKTOR PROPERTY DAN REAL ESTATE YANG TERDAFTAR DI ISSI TAHUN $(2013-2015){ }^{1)}$
}

\author{
Nadia Amalia Latifah \\ Mahasiswa Program Studi Ekonomi Islam - Fakultas Ekonomi dan Bisnis Universitas Airlangga \\ Email: nadia.amalia-13@feb.unair.ac.id \\ Nisful Laila \\ Departemen Ekonomi Syariah - Fakultas Ekonomi dan Bisnis - Universitas Airlangga \\ Email: nisful.laila@ feb.unair.ac.id
}

\begin{abstract}
:
Islamic stocks is one of the most preffered investment type by Muslim investors. In the decision making process, the investors have to consider the financial reports and stock analysis. This research aim to investigate the effect of fundamental performance toward stock return property and real estate registered in ISSI in 2013 - 2015. Dependent variable is stock return and the independent variable are Return on Equity, Earning per Share, and Debt to Equity Ratio.

The research used quantitative approach using secondary data. This research used panel data regression method. This research collecting data from the annual report from 2013 to 2015. This research used a significance level of $5 \%$.

Based on the regression analysis result, it indicate that ROE does not have significant effect to the stock returns. EPS and DER have significant effect to the stock returns. Simultaneously, ROE, EPS and DER have significant effect to the stock returns.
\end{abstract}

Keywords: Return On Equity (ROE), Earning Per Share (EPS), dan Debt to Equity Ratio (DER), Stock Return, Indonesia Sharia Stock Index

\section{I0. PENDAHULUAN}

\section{Latar Belakang}

Perkembangan zaman, kebutuhan

hidup mengalami peningkatan harga yang diakibatkan oleh inflasi. Masyarakat harus memikirkan untuk dapat mengelola keuangannya agar memperoleh pendapatannya dimasa depan dengan cara berinvestasi. . Era global ini, mulai muncul suatu perusahaan dan lembaga kevangan yang berbasis syariah. Umat Islam telah diberi kemudahan untuk melakukan investasi secara syariah tanpa adanya riba. Pasar modal syariah telah menjamah untuk memenuhi kepentingan bagi investor Islam sehingga emiten merubah sistem kegiatan bisnisnya dengan berbasis syariah tanpa melanggar syariahlslam. Kegiatan pasar modal di Indonesia, melakukan kegiatan yang bersangkutan dengan penawaran umum dan perdagangan efek dengan perusahaan publik yang menerbitkan efek

(Tandelilin, 2010:27).

Salah satu instrumen keuangan yang berbasiskan syariah pada kegiatan pasar modal yaitu saham syariah. Saham syariah adalah sertifikat yang menunjukkan bukti kepemilikan suatu perusahaan yang diterbitkan oleh emiten, emiten membutuhkan dana dari investor 
Latifah, et al/Jurnal Ekonomi Syariah Teori dan Terapan Vol. 4 No. 12 Desember 2017: 1009-1023; PENGARUH RETURN ON EQUITY, EARNING PER SHARE, DAN DEBT TO EQUITY RATIO TERHADAP RETURN SAHAM (STUDI PADA EMITEN SAHAM SYARIAH SEKTOR PROPERTY DAN REAL ESTATE YANG TERDAFTAR DI ISSI TAHUN (2013- 2015)

yang meminta imbal hasil dari keuntungan yang diperoleh dari kegiatan usaha, dengan syarat perusahaan tersebut kegiatan usahanya maupun cara pengelolaanya tidak bertentangan dengan prinsip syariah.Pemilihan keputusan investor melihat dari kinerja kevangan perusahaan dan return saham. Return saham adalah keuntungan yang diperoleh perusahaan karena keberhasilannya dalam mengelola usahanya dan hasil tersebut dapat memberikan bagi hasil kepada investor yang telah meminjamkan modalnya (Tandelilin, 2010:102).

Perkembangan pada teknologi dan informasi dari penjuru dunia, property dan real estate yaitu salah satu aset kepemilikan berupa tanah dan manfaat yang juga berada di dalamnya. Perkembangan perusahaan property dan real estate terlihat pada grafik 1.1 makin tahun ke tahun mengalami peningkatan pada indeks poin.

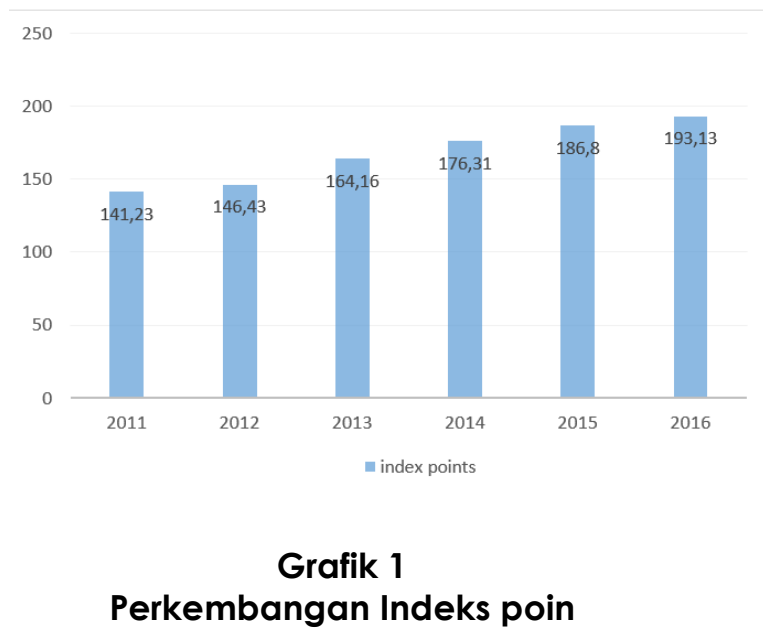

Sumber: www.tradingeconomics.com
Diharapkan pada tahun berikutnya terus mengalami perkembangan dengan masyarakat yang sudah masa pensiun dapat berinvestasi pada saham di perusahaan property dan real estate. Meskipun industri property dan real estate dipengaruhi oleh ekonomi makro, namun tetap berusaha memperoleh keuntungan dalam penjualannya. Hal tersebut mempengaruhi harga saham yang selalu mengalami fluktuasi harga membuat return saham yang diberikan juga mengalami perubahan. Penelitian ini, penulis akan menganalisis kinerja keuangan perusahaan property dan real estate yang terdaftar pada ISSI berdasarkan rasio Return on Equity (ROE), Earning Per Share (EPS), dan Debt to Equity Ratio (DER) yang dapat dilihat pada Tabel 1.1

Tabel 1

Return, ROE, EPS, DER

\begin{tabular}{|c|c|c|c|c|}
\hline Tahun & Return Saham & ROE & EPS & DER \\
\hline 2013 & $46 \%$ & $17 \%$ & Rp 150,03 & $91 \%$ \\
\hline 2014 & $38 \%$ & $14 \%$ & Rp 168,78 & $85 \%$ \\
\hline 2015 & $-10 \%$ & $12 \%$ & Rp 181,31 & $83 \%$ \\
\hline
\end{tabular}

sumber : data diolah penulis

Return saham pada perusahaan property dan real estate pada tiga tahun terakhir mengalami penurunan.Minat permintaan pada saham tersebut mengalami penurunan dengan diikuti harga saham menurun. Kemungkinan saat itu investor ragu karena dimana kondisi perekonomian mengalami penurunan dan suku bunga meningkat, sehingga 
Latifah, et al/Jurnal Ekonomi Syariah Teori dan Terapan Vol. 4 No. 12 Desember 2017: 1009-1023; PENGARUH RETURN ON EQUITY, EARNING PER SHARE, DAN DEBT TO EQUITY RATIO TERHADAP RETURN SAHAM (STUDI PADA EMITEN SAHAM SYARIAH SEKTOR PROPERTY DAN REAL ESTATE YANG TERDAFTAR DI ISSI TAHUN (2013 - 2015)

mengakibatkan penurunan harga saham.

Perusahaan property dan real estate adalah industri yang peka terhadap suku bunga sehingga investor tahu kekurangan yang dimiliki perusahaan tersebut (Husnan, 2009:325).

Return on Equity karena untuk mengukur perusahaan dapat mengembalikan vang dari para pemegang saham dan menunjukkan besarnya pengembalian tersebut. Penurunan kinerja keuangan memberikan dampak bagi calon investor untuk berinvestasi di perusahaan tersebut. Hasil tabel Return on Equity (ROE) menglami penurunan, mungkin disebabkan oleh kebijakan pemerintah untuk membangun perumahan dengan harga murah agar kalangan menengah dapat membelinya (Kasmir, 2015:204).

Earning per Share untuk mengukur perusahaan dalam efektivitas manjamennya dalam mencapai keuntungan bagi para pemegang saham. Laba per saham mengalami peningkatan, sehingga kinerja perusahaan tersebut mengalami kondisi baik, meskipun terdapat kondisi ekonomi maupun kondisi politik (Kasmir, 2015:207).

Debt to equity ratio (DER)untuk mengukur perusahaan didanai oleh hutang untuk dapat menjalankan operasional perusahaan. Rasio DER mengalami penurunan, perusahaan sudah baik untuk meminimalkan hutangnya. Hal itu membuat ketertarikan investor berinvestasi di perusahaan tersebut, maka menyebabkan return saham meningkat karena harga saham meningkat (Kasmir, 2015:157).

Hasil penelitian sebelumnya masih terdapat hasil yang bervariatif. Peneliti tertarik untuk meneliti pengaruh kinerja keuangan terhadap return saham syariah. Berkembanganya perusahaan property dan real estate di Indonesia dengan meningkatkan penjualannya untuk memenuhi permintaan konsumen. Maka emiten berusaha dengan baik agar memperoleh return yang besar. Investor untuk memilih tempat yang tepat untuk berinvestasi di perusahaan tersebut, dengan melihat kinerja keuangan perusahaan (Kweon, dkk, 1999:77). Maka penulis tertarik untuk menguji penelitian ini dengan dengan judul "Pengaruh Return on Equity (ROE), Earning Per Share (EPS), dan Debt to Equity Ratio (DER) terhadap Return Saham pada Perusahaan PropertydanReal Estate yang Terdaftar di Indeks Saham Syariah Indonesia Tahun 2013 - 2015".

Rumusan Masalah

Berdasarkan latar belakang masalah, maka dapat dirumuskan permasalaha berikut :

1. Apakah return on equity, earning per share dan debt to equity ratioberpengaruh signifikan terhadap return saham secara parsial pada perusahaanproperty dan real estate 
Latifah, et al/Jurnal Ekonomi Syariah Teori dan Terapan Vol. 4 No. 12 Desember 2017: 1009-1023; PENGARUH RETURN ON EQUITY, EARNING PER SHARE, DAN DEBT TO EQUITY RATIO TERHADAP RETURN SAHAM (STUDI PADA EMITEN SAHAM SYARIAH SEKTOR PROPERTY DAN REAL ESTATE YANG TERDAFTAR DI ISSI TAHUN (2013- 2015)

yang terdaftar di ISSI tahun 2013 2015 ?

2. Apakah return on equity, earning per share dan debt to equity ratioberpengaruh signifikan terhadap return saham secara simultan pada perusahaanproperty dan real estate yang terdaftar di ISSI tahun 2013 2015 ?

Tujuan Penelitian

Berdasarakan rumusan masalah diatas maka tujuan penelitian ini adalah :

1. Untuk mengetahui pengaruh secara return on equity, earning per share dan debt to equity ratioterhadap returnsaham secara parsial pada perusahaan property dan real estate yang terdaftar di ISSI tahun 2013 2015.

2. Untuk mengetahui pengaruh return on equity, earning per share dan debt to equity ratioterhadap return saham secara simultan pada perusahaan property dan real estate yang terdaftar di ISSI tahun 2013 - 2015.

\section{TINJAUAN PUSTAKA}

\section{Investasi Syariah}

Menurut Hidayat (2011:24-25)

investasi dalam Islam adalah salah satu cara dalam mengelola hartanya agar dapat harta tersebut berkembang secara produktif dengan etika yang benar yang dilandasi oleh Al - Qur'an dan hadits. Aktivitas investasi mengandung hal - hal sebagai berikut: (1) memiliki tujuan yang spesifik, (2) jumlah dana yang dibutuhkan terukur, (3) jelas angka waktunya, (4) sebagai alternatif instrumen investasi, dan (5) memiliki strategi untuk mencapai tujuan tersebut.

\section{PASAR MODAL SYARIAH}

Perkembangan pasar modal yang berbasis syariah di Indonesia yang ditetapkan oleh Badan Pengawas Pasar Modal (Bapepam) bahwa pasar modal syariah juga dapat mengembangkan pada pasar modal di Indonesia. Bapepam merancang sebuah dua strategi utama untuk mencapai pengembangan pasar modal syariah dan produk pasar modal syariah. Pertama ialah mengembangkan kerangka hukum untuk memfasilitasi pengembangan pasar modal berbasis syariah. Kedua, mendorong pengembangan produk pasar modal berbasis syariah. Kedua strategi tersebut yang dijabarkan oleh Bapepam menjadi tujuh implementasi strategi (Huda, 2007:58) :

1. Harus sesuai dengan peraturan yang berprinsip syariah;

2. Menyusun standar akuntansi;

3. Mengembangkan profesi pelaku pasar;

4. Sosialisasi prinsip syariah;

5. Mengembangkan produk;

6. Menciptakan produk baru;

7. Meningkatkan kerja sama dengan Dewan Syariah Nasional (DSN) MUI.

\section{Saham Syariah}

Menurut Hidayat (2011:78) saham syariah adalah emiten mengeluarkan bukti kepemilikan atas suatu perusahaan pada jenis usaha, produk barang, jasa 
Latifah, et al/Jurnal Ekonomi Syariah Teori dan Terapan Vol. 4 No. 12 Desember 2017: 1009-1023; PENGARUH RETURN ON EQUITY, EARNING PER SHARE, DAN DEBT TO EQUITY RATIO TERHADAP RETURN SAHAM (STUDI PADA EMITEN SAHAM SYARIAH SEKTOR PROPERTY DAN REAL ESTATE YANG TERDAFTAR DI ISSI TAHUN (2013- 2015)

yang diberikan dan akad serta cara pengelolaan tidak bertentangan dengan prinsip - prinsip syariah (dan pada saham syariah berbeda dengan saham preferen yang memiliki hak - hak istimewa.

Perusahaan yang memiliki saham syariah harus sesuai dengan kriteria-kriteria yang telah ditetapkan oleh Dewan Syariah Nasional-Majelis Ulama Indonesia (DSN-MUI) yang diatur oleh Peraturan Bapepam-LK, Nomor II. K.1 yaitu tentang kriteria dan Penerbitasn Daftar Efek Syariah sebagai berikut (Sutedi, 2011:35):

1. Tidak melakukan kegiatan usaha yang bertentangan dengan prinsip syariah:

a. Meneyelenggarakan jasa keuangan yang menerapakna konsep ribawai, jual beli risiko mengandung gharar dan atau maysir,

b. Memproduksi, mendistribusikan/jasa haram karena zatnya (haram li dzatihi), barang/jasa haram bukan karena zatnya (haram lighairihi) yang ditetapkan oleh DSN-MUI, serta barang/jasa yang merusak moral dan bersifat mudharat.

2. Tidak melakukan perdagangan yang tidak disertasi penyerahan barang/jasa.

3. Tidak melakukan perdagangan dengan penawaran atau permintaan palsu.

4. Tidak melebihi rasio - rasio keuangan sebagai berikut:

a. Total utang berbasis bunga: total ekuitas $82 \%$; b. Total pendapatan bunga dan pendapatan nonhalal lainnya total pendapatan (revenue) $10 \%$.

\section{Rasio Kevangan}

Penggunaan rasio untuk meramal masa depan suatu perusahaan. Rasio tersebut dari laporan kevangan yang sama (neraca atau laporan laba - rugi), dan menggunakan komponen dua laporan yang berbeda. Analis membandingkan rasio perusahaan dengan rata - rata rasio perusahaan di industri yang sama untuk mendeteksi perbedaan yang perlu dipertimbangkan lebih lanjut. Rasio keuangan menganalisis trend rasio perusahaan sepanjang waktu, berharap trend ini dapat membantu investor untuk meramalkan perubahan masa depan. Rasio keuangan dan analisis teknis dikombinasi untuk mencapai keputusan investasi. (Sharpe, dkk, 1997:376)

Menurut Brigham dan Houston (2001:78) analisis rasio keuangan digunakan untuk sebagai berikut:

1. Bagi pandangan investor untuk memprediksi masa mendatang

2. Segi pandang manajemen, untuk membantu mangantipisipasi kondisi di masa depan.

3. Hal yang penting adalah sebagai titik awal untuk perencanaan tindakan yang akan terjadi atau dapat memperngaruhi peristiwa di masa depan. 
Latifah, et al/Jurnal Ekonomi Syariah Teori dan Terapan Vol. 4 No. 12 Desember 2017: 1009-1023; PENGARUH RETURN ON EQUITY, EARNING PER SHARE, DAN DEBT TO EQUITY RATIO TERHADAP RETURN SAHAM (STUDI PADA EMITEN SAHAM SYARIAH SEKTOR PROPERTY DAN REAL ESTATE YANG TERDAFTAR DI ISSI TAHUN (2013- 2015)

Return Saham

$$
\text { Return menurut Tandelilin }
$$

(2010:102) adalah imbalan bagi para investor yang telah membeli saham atau meminjamkan dananya bagi perusahaan yang menanggung risiko atas investasi yang dilakukannya, sehingga membuat motivasi bagi investor lainnya untuk berinvestasi karena akan menerima keuntungan yang besar. Return investasi terdiri dari yield dan capital gain (loss).

$$
\text { Yield (jogiyanto, 2010:206) }
$$

merupakan presentase dividen pada harga saham tiap periode. Sedangkan capital gain (loss) sebagai return dari kenaikan (penurunan) harga suatu surat berharga. Return saham adalah capital gain (loss) yang dihitung dari perubahan harga saham setahun dan dibagi dengan harga awal tahun dapat dihitung dengan rumus (Jogiyanto, 2010:206).

$$
R_{t}=\frac{P_{\dagger}-P_{t-1}}{P_{t-1}}
$$

Keterangan :

$\mathrm{R}_{\dagger} \quad=$ Return Saham

$\mathrm{P}_{\dagger} \quad=$ Harga saham pada tahun saat ini

$\mathrm{P}_{\mathrm{t}-1}=$ Harga saham pada tahun sebelumnya

\section{Return on Equity}

Return on equity (ROE) menurut Tandelilin (2010:372) adalah kemampuan perusahaan menghasilkan laba dan dapat memberikan imbal hasil kepada pemegang saham. Semakinbesar return on equity, maka semakin besar tingkat keuntungan yang dicapai suatu perusahaan sehingga kondisi yang bermasalah semakin kecil. Secara matematis, rumus menghitung ROE sebagai berikut (Kasmir, 2015:204).

ROE $=\underline{\text { Laba Bersih }}$ Jumlah Ekuitas

\section{Earning Per Share}

Menurut Samsul (2006:167) earning per share ialah investor yang membeli saham akan tercermin pada laba per saham. Rasio ini membagi laba bersih dan jumlah saham. Jika laba per saham rendah berarti kinerja keuangan kurang baik, memperoleh return yang kecil. Prospek perusahaan yang baik adalah laba per saham lebih tinggi. Secara matematis, rumus menghitung EPS sebagai berikut (Keown, dkk, 1999:103) :

EPS $=\underline{\text { Laba Bersih Sesudah Pajak }}$

\section{Debt to Equity Ratio}

Menurut Kasmir (2015:158) Debt to equity ratio digunakan untuk mengetahui setiap rupiah modal sendiri perusahaan yang dijaadikan sebagai jaminan utang. Rasio DER meningkat, pada sisi bank (kreditor) perusahaan tersebut akan mengalami risiko besar karena hutang yang semakin besar mengakibatkan kurang minatnya para investor untuk berinvestasi. Namun, bagi perusahaan justru semakin besar rasio yang diperoleh, maka semakin baik perusahaan tersebut. Rumus DER (Susilo, 2009:69) adalah sebagai berikut:

DER $=\underline{\text { Total Liabilitas }}$ 
Latifah, et al/Jurnal Ekonomi Syariah Teori dan Terapan Vol. 4 No. 12 Desember 2017: 1009-1023; PENGARUH RETURN ON EQUITY, EARNING PER SHARE, DAN DEBT TO EQUITY RATIO TERHADAP RETURN SAHAM (STUDI PADA EMITEN SAHAM SYARIAH SEKTOR PROPERTY DAN REAL ESTATE YANG TERDAFTAR DI ISSI TAHUN (2013- 2015)

Total Ekuitas

\section{Hipotesis}

Berdasarkan tujuan penelitian ini hipotesis yang digunakan dalam penelitian ini adalah

$\mathrm{Hl}$ : Return on Equity (ROE) berpengaruh signifikan secara parsial terhadap return saham pada perusahaan property dan real estate yang terdaftar di ISSI tahun 2013 - 2015

H2 : Earning Per Share (EPS) berpengaruh signifikan secara parsial terhadap return saham pada perusahaan property dan real estate yang terdaftar di ISSI tahun 2013 - 2015

H3: Debt to Equity Ratio (DER) berpengaruh signifikan secara parsial terhadap return saham pada perusahaan property dan real estate yang terdaftar di ISSI tahun 2013 2015

H4: Return on eqiuty, Earning Per Share dan Debt to Equity Ratio berpengaruh signifikan terhadap return saham pada perusahaan property dan real estate yang terdaftar di ISSI tahun $2013-2015$

\section{Model Analisis}

Model analisis agar mengetahui ada pengaruh kinerja keuangan terhadap return saham pada perusahaan property dan real estate yang terdaftar pada ISSI.

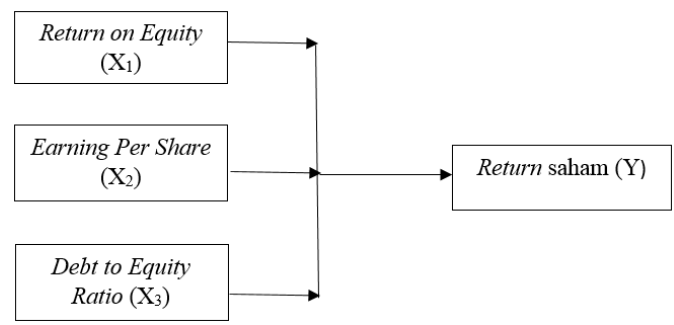

Gambar 2.1

Model Analisis

Sumber : Diolah Penulis

\section{METODE PENELITIAN}

Pendekatan penelitian ini menggunakan pendekatan kuantitatif dengan menggunakan data sekunder yang memiliki dua variabel yang akan diteliti. Variabel dependen adalah return saham perusahaan property dan real estate yang terdaftar di ISSI tahun 2013 2015. Serta variabel independen diwakili oleh Return on Equity, Earning Per Share, dan Debt to Equity Ratio.

Pengujian hipotesis pada penelitian ini dilakukan menggukan uji $\dagger$ untuk menguji variabel independen berpengaruh signifikan secara parsial terhadap return saham dan uji $F$ untuk menguji variabel independen berpengaruh signifikan secara simultan terhadap return saham. Penelitian ini menggunakan tingkat signifikansi sebesar 5\%. Koefisien determinasi untuk mengetahui seberapa besar variabel independen berpengaruh terhadap variabel dependen.

Penelitian ini menggunakan regresi data panel yaitu penggabungan cross section (beberapa emiten tertentu) dan data time series(lingkup waktu dari tahun 2013 - 2015).Perlu menentukan estimasi model regresi panel, dengan beberapa uji untuk memilih yang sesuai dengan metode pendekatan estimasi. Langkah pertama ialah melakukan uji Chow pada hasil estimasi menentukan antara FEM 
Latifah, et al/Jurnal Ekonomi Syariah Teori dan Terapan Vol. 4 No. 12 Desember 2017: 1009-1023; PENGARUH RETURN ON EQUITY, EARNING PER SHARE, DAN DEBT TO EQUITY RATIO TERHADAP RETURN SAHAM (STUDI PADA EMITEN SAHAM SYARIAH SEKTOR PROPERTY DAN REAL ESTATE YANG TERDAFTAR DI ISSI TAHUN (2013- 2015)

atau CEM. Jika ditemukan efek individu, maka melakukan uji Hausman untuk menentukan antara FEM dan REM.

Populasi dalam penelitian ini adalah semua perusahaan property dan real estate yang go public yang terdaftar di Bursa Efek Indonesia (BEI) periode tahun 2013-2015. Sampel menggunakan teknik purposive sampling, dengan kriteria yaitu perusahaan property dan real estate yang listed di ISSI yang menetap berturut - turut dari tahun 2013 - 2015. Perusahaan yang sesuai kriteria dari tahun 2013 - 2015 didapatkan 31 perusahaan property dan real estate yang siap untuk diteliti.

\section{DEFINISI OPERASIONAL}

\begin{tabular}{|c|c|c|}
\hline No. & Variabel & Rumus \\
\hline 1. & $\begin{array}{l}\text { Return On } \\
\text { Equity }\end{array}$ & $\begin{array}{r}\text { ROE }=\underline{\text { Laba Bersih }} \\
\text { Jumlah ekuitas }\end{array}$ \\
\hline 2. & $\begin{array}{l}\text { Earning } \\
\text { Per Share }\end{array}$ & $\begin{array}{l}\text { EPS }=\underline{\text { Laba Bersih }} \\
\text { Jumlah Saham Beredar }\end{array}$ \\
\hline 3. & $\begin{array}{l}\text { Debt to } \\
\text { Equity } \\
\text { Ratio }\end{array}$ & $\begin{array}{l}\text { DER = } \underline{\text { Total Liabilitas }} \\
\text { Total Ekuitas }\end{array}$ \\
\hline 4. & $\begin{array}{l}\text { Return } \\
\text { Saham }\end{array}$ & $R_{t}={\underline{P_{t}-P_{t-1}}}_{P_{t-1}}$ \\
\hline
\end{tabular}

Sumber:Kasmir:2015;Susilo:2009; Jogiyanto: 2010, diolah penulis

\section{HASIL DAN PEMBAHASAN \\ Uji Chow}

Tabel 4.1

Hasil Eviews 8.0 Uji chow

Equation: Untitled

Test cross-section fixed effect

\begin{tabular}{lcrc}
\hline \hline Effects Test & Statistic & d.f. & Prob. \\
\hline \hline Cross-section F & 1.141981 & $(30,59)$ & 0.3250 \\
Cross-section Chi-square & 42.579842 & 30 & 0.0638 \\
\hline \hline
\end{tabular}

Cross-section fixed effects test equation:

Dependent Variable: RETURN

Method: Panel Least Squares

Date: 01/13/17 Time: $14: 40$

Sample: 20132015

Periods included: 3

Cross-sections included: 31

Total panel (balanced) observations: 93

\begin{tabular}{lrllr}
\hline \hline \multicolumn{1}{c}{ Variable } & Coefficient & Std. Error & t-Statistic & Prob. \\
\hline \hline R & -0.782568 & 0.308683 & -2.535178 & 0.0130 \\
ROE & 1.219552 & 1.329837 & 0.917068 & 0.3616 \\
EPS & 0.001027 & 0.000433 & 2.370810 & 0.0199 \\
DER & 0.790385 & 0.280111 & 2.821681 & 0.0059 \\
\hline \hline R-squared & 0.175768 & Mean dependent var & 0.247976 \\
Adjusted R-squared & 0.147985 & S.D. dependent var & 1.289431 \\
S.E. of regression & 1.190205 & Akaike info criterion & 3.228187 \\
Sum squared resid & 126.0764 & Schwarz criterion & 3.337116 \\
Log likelihood & -146.1107 & Hannan-Quinn criter. & 3.272170 \\
F-statistic & 6.326437 & Durbin-Watson stat & 2.084731 \\
Prob(F-statistic) & 0.000614 & & & \\
\hline \hline
\end{tabular}

Sumber : Hasil olah data

Berdasarkan hasil pengujian uji chow pada tabel 4.1 didapatkan p-Valve> 0,05 maka hipotesis $\mathrm{H}_{0}$ diterima. P-Valve $(0,3250)>0,05$ maka hipotesis yang diterima ialah $\mathrm{H}_{0}$, dengan menolak $\mathrm{H}_{1}$. Berdasarkan uji Chow diperoleh pemilihan model yang sesuai adalah menggunakan model Pooled Least Square (PLS).

\section{Uji CEM}

Tabel 4.2

Dependent Variable: RETURN

Hasil Eviews 8.0 Uji PLS

Method: Panel Least Squares

Date: $01 / 13 / 17$ Time: $14: 33$

Sample: 20132015

Periods included: 3

Cross-sections included: 31

Total panel (balanced) observations: 93

\begin{tabular}{lrlll}
\hline \hline \multicolumn{1}{c}{ Variable } & Coefficient & Std. Error & t-Statistic & Prob. \\
\hline \hline C & -0.782568 & 0.308683 & -2.535178 & 0.0130 \\
ROE & 1.219552 & 1.329837 & 0.917068 & 0.3616 \\
EPS & 0.001027 & 0.000433 & 2.370810 & 0.0199 \\
DER & 0.790385 & 0.280111 & 2.821681 & 0.0059 \\
\hline \hline R-squared & 0.175768 & Mean dependent var & 0.247976 \\
Adjusted R-squared & 0.147985 & S.D. dependent var & 1.289431 \\
S.E. of regression & 1.190205 & Akaike info criterion & 3.228187 \\
Sum squared resid & 126.0764 & Schwarz criterion & 3.337116 \\
Log likelihood & -146.1107 & Hannan-Quinn criter. & 3.272170 \\
F-statistic & 6.326437 & Durbin-Watson stat & 2.084731 \\
Prob(F-statistic) & 0.000614 & & & \\
\hline \hline
\end{tabular}

Sumber: Hasil olah data 
Latifah, et al/Jurnal Ekonomi Syariah Teori dan Terapan Vol. 4 No. 12 Desember 2017: 1009-1023; PENGARUH RETURN ON EQUITY, EARNING PER SHARE, DAN DEBT TO EQUITY RATIO TERHADAP RETURN SAHAM (STUDI PADA EMITEN SAHAM SYARIAH SEKTOR PROPERTY DAN REAL ESTATE YANG TERDAFTAR DI ISSI TAHUN (2013- 2015)

Tabel 4.1 tertera hasil estimasi model PLS yang mendapatkan nilai RSquared sebesar 17,5768\%. Variabel independen hanya dapat menjelaskan variabilitas dependen (return saham) sebesar 17,5768\%. Sedangkan sisanya dijelaskan oleh variabel lain yang tidak diteliti oleh peneliti atau tidak masuk ke dalam model.

Uji $†$

Tabel 4.3

Output Eviews 8.0 Hasil Estimasi Uji $\uparrow$

\begin{tabular}{|c|c|c|c}
\hline Variabel & Probability & Loss $(\alpha)$ & Keterangan \\
\hline ROE & 0,3616 & \multirow{3}{*}{0,05} & Nilai prob $>(\alpha): \mathrm{H}_{0}$ diter \\
\cline { 1 - 1 } & 0,0199 & & Nilai prob $<(\alpha): \mathrm{H}_{0}$ ditol \\
& 0,0059 & & Nilai prob $<(\alpha): \mathrm{H}_{0}$ ditol \\
\hline DER & 0, &
\end{tabular}

Sumber: Data diolah

Berdasarkan pengujian pada tabel

4.3 dapat disimpulkan sebagai berikut:

1. ROE : Ho diterima, dapat disimpulkan bahwa ROE berpengaruh tidak signifikan secara parsial terhadap return saham.

2. EPS : $\mathrm{H}_{0}$ ditolak, dapat disimpulkan bahwa EPS berpengaruh signifikan secara parsial terhadap return saham.

3. DER : Ho ditolak, dapat disimpulkan bahwa DER berpengaruh signifikan secara parsial terhadap return saham.

Uji F

Tabel 4.4

Output Eviews 8.0 Hasil Uji Statistik F

\begin{tabular}{|l|l|}
\hline F-hitung & 6,326437 \\
\hline Prob(F-statistic) & 0,000614 \\
\hline
\end{tabular}

Sumber: Data diolah
Berdasarkan pada tabel 4.4 nillai Fhitung adalah 6,326437 dan hasil nilai probability $\mathrm{F}$ adalah 0,000614 kurang dari a $(0,05)$ artinya pada penelitian ini dapat disimpulkan bahwa variabel ROE, EPS, dan DER berpengaruh secara signifikan secara simultan terhadap return saham pada perusahaan property dan real estate yang terdaftar di ISSI tahun 2013 - 2015.

\section{Uji $R^{2}$ (R-Square)}

Pada model PLS memberikan nilai Rsquared dengan sebesar 17,6\%. Artinya, variabel independen dapat menjelaskan variabilitas dependen return saham sebesar $17,6 \%$, sedangkan sisanya sebesar $82,4 \%$ adalah variabel lain yang belum masuk dalam model.

\section{Pembahasan}

a. Return on Equity berpengaruh positif dan tidak signifikan terhadap return saham. Rasio ROE berpengaruh positif berarti, ROE yang tinggi maka semakin tinggi harga saham meningkat dan menghasilkan return saham meningkat. Namun, pada penelitian ini ROE tidak berpengaruh signifikan terhadap return saham. Sejalan dengan penilitian Ganto, dkk (2008) dan Susilowati (2011) berpengaruh positif dan tidak signifikan terhadap return saham.

Hasil dari penelitian Susilowati (2011) bahwa hasil dari pengujian bertenatangan dengan teori Return on Equity, karena para pemegang saham ingin mengetahui tingkat profitabilitas modal saham dan bagi para pemodal digunakan untuk efektifitas dana 
Latifah, et al/Jurnal Ekonomi Syariah Teori dan Terapan Vol. 4 No. 12 Desember 2017: 1009-1023; PENGARUH RETURN ON EQUITY, EARNING PER SHARE, DAN DEBT TO EQUITY RATIO TERHADAP RETURN SAHAM (STUDI PADA EMITEN SAHAM SYARIAH SEKTOR PROPERTY DAN REAL ESTATE YANG TERDAFTAR DI ISSI TAHUN (2013- 2015)

pemegang saham yang telah diinvestasikan. Apabila saham perusahaan diperdagangkan pada bursa, maka tinggi rendahnya rasio ROE akan mempengaruhi tingkat permintaan saham di bursa dan harga jualnya.

b. Earning Per Share berpengaruh positif dan signifikan terhadap return saham. Rasio EPS yang tinggi maka semakin tinggi harga saham meningkat dan menghasilkan return saham meningkat. Minat investor berinvestasi pada perusahaan tersebut karena rasio EPS meningkat, sehingga return saham meningkat. Penelitian ini sejalan dengan Adi, dkk (2013) bahwa EPS berpengaruh positif dan signifikan terhadap harga saham.

Surat Huud ayat 85 menjelaskan keuntungan yang diterima dari Allah karena telah melakukan usaha sudah sesuai koridor Islam.

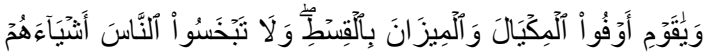

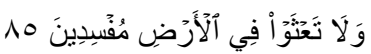

Syu'aib berkata: "Hai kaumku, cukupkanlah takaran dan janganlah kamu merugikan manusia terhadap hak hak mereka dan janganlah kamu membuat kejahatan di muka bumi dengan membuat kerusakan" (Q.S HuUd: 85) (Departemen Agama, 2005:332)

Keuntungan yang diterima oleh perusahaan berasal dari kegiatan usahanya yang telah sesuai dengan syariat Islam, harap didasari rasa bersyukur karena Allah telah memberikan rezeki lebih bagi perusahaan. Perusahaan yang mendapatkan pendapatan yang dianugrahkan oleh Allah SWT, harap menepati perjanjian dengan memberi pendapatan yang sesuai dengan takaran dan timbangan kepada pemegang saham. Jangan sampai perusahaan mengambil takaran atau harta orang lain

c. Debt to Equity Ratio

Debt to Equity Ratio berpengaruh positif dan signifikan terhadap return saham. Hasil tersebut bertentangan dengan teori, bila rasio DER meningkat maka return saham akan menurun. Perusahaan selain menggunakan dana internal, juga menggunakan dana dari eksternal (hutang). Tujuan dagang ialah untuk meraih laba dengan proses pemutaran modal dan pengoperasiannya dalam aksi - aksi dagang dan moneter. Perusahaan dapat leluasa menjalankan operasionalnya dan memperoleh laba. Keuntungan yang semakin tinggi maka akan meningkatkan return saham. Probablitas adalah kemungkinan hasil pengembalian dari suatu investasi. Bila perusahaan memiliki laba yang inggi, maka akan membayar jumlah dividen besar, dan menikmati keuntungan modal yang besar pula (Brigham dan Houston, 2010:325).

Pemegang saham selain melihat leverage yang tinggi atau rasio DER yang tinggi, investor melihat dari sisi probabilitas perusahaan. Jika tingkat 
Latifah, et al/Jurnal Ekonomi Syariah Teori dan Terapan Vol. 4 No. 12 Desember 2017: 1009-1023; PENGARUH RETURN ON EQUITY, EARNING PER SHARE, DAN DEBT TO EQUITY RATIO TERHADAP RETURN SAHAM (STUDI PADA EMITEN SAHAM SYARIAH SEKTOR PROPERTY DAN REAL ESTATE YANG TERDAFTAR DI ISSI TAHUN (2013 - 2015)

probabilitas meningkat, maka akan meningkatkan permintaan pada saham perusahaan tersebut dan meningkatkan hasil pengembalian atau return saham.

Hasil penelitian ini konsisten dengan penelitian Susilowati (2011) bahwa DER pengaruh positif dan signifikan terhadap return saham. Perusahaan yang memiliki hutang kepada kreditor, harap memberikan jaminan dan segera melunasi hutangnya, agar kreditor percaya terhadap perusahaan tersebut. Allah telah menegaskan kepada para umat muslim agar segera membayar hutang, seperti dalam hadist HR. Al-Bukhari 2212 yaitu sebagai berikut:

$$
\begin{aligned}
& \text { عَنْ أَبِي الغَيْثِ، عَنْ أَبِيِ هُرَيْرَة رَضِيَ اللَّهُ عَنْهُ، عَنِ النَّبِّ } \\
& \text { صَلَّى اللهُ عَلَيْهِ وَسَلَّمَ قَالَ: المَنْ أَخَذَ أَمْوَالَ النَّاسِ يُرِيدُ }
\end{aligned}
$$

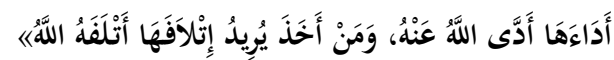

"Siapa yang mengambil harta manusia (berhutang) disertai maksud membayarnya maka Allah akan membayarkannya untuknya, sebaliknya siapa yang mengambilnya dengan maksud merusaknya (merugikannya) maka Allah akan merusak orang itu" (HR Al-Bukhari no 2212) (Bukhari, 2016:1308)

Perusahaan berusaha sebaik mungkin dan bekerja keras untuk memperoleh keuntungan dikarenakan ketatnya persaingan dan faktor - faktor lain yang mengakibatkan usaha tersebut menjadi terhambat memperoleh keuntungan. Perusahaan yang memperoleh keuntungan tersebut bisa membayar utang - utangnya, dan dapat memberikan bagi hasilnya kepada para pemegang saham.

d. Return on Equity (ROE), Earning per Share (EPS), dan Debt to Equity Ratio (DER) berpengaruh secara signifikan secara simultan terhadap return saham pada perusahaan property dan real estate yang terdaftar di ISSI tahun 2013 - 2015. Sebagai seorang investor muslim dalam memilih tempat yang tepat untuk berinvestasi bisa melihat dari rasio Return on Equity (ROE), Earning per Share (EPS), dan Debt to Equity Ratio (DER). Namun dianjurkan para investor melihat dari faktor - faktor lain yang diluar dari penelitian. Bagi investor juga mengacu pada perusahaan return saham yang tinggi, agar investor aman dalam menanamkan dananya pada perusahaan tersebut. Namun, para pemagang saham harus tetap waspada karena perusahaan tidak tahu akan menghasilkan keuntungan ataupun kerugian. Bagi kedua belah pihak tidak tahu resiko yang akan terjadi, karena hanya Allah yang mengetahui. Seperti pada surat Al Luaman ayat 34 :

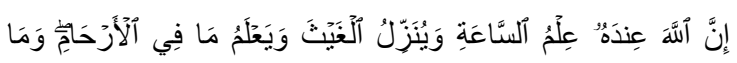

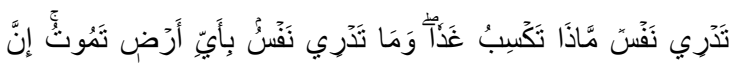

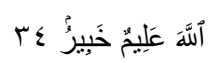

"Sesungguhnya Allah, hanya pada sisi-Nya sajalah pengetahuan tentang hari kiamat; 
Latifah, et al/Jurnal Ekonomi Syariah Teori dan Terapan Vol. 4 No. 12 Desember 2017: 1009-1023; PENGARUH RETURN ON EQUITY, EARNING PER SHARE, DAN DEBT TO EQUITY RATIO TERHADAP RETURN SAHAM (STUDI PADA EMITEN SAHAM SYARIAH SEKTOR PROPERTY DAN REAL ESTATE YANG TERDAFTAR DI ISSI TAHUN (2013- 2015)

dan Dialah yang menurunkan hujan, dan mengetahui apa yang ada dalam rahim. Dan tiada seorang pun yang dapat mengetahui dengan pasti apa yang akan diusahakan besok. Dan tiada seorang pun yang dapat mengetahui di bumi mana dia akan mati. Sesungguhnya Allah Maha Mengetahui lagi Maha Mengenal." (Q.S. AlLuqman:34) (Departemen Agama, 2005:648)

\section{SIMPULAN}

Berdasarkan pembahasan hasil dari penelitian yang telah dilakukan mengenai pengaruh Return on Equity (ROE), Earning per Share (EPS), dan Debt to Equity Ratio (DER) terhadap return saham perusahaan property dan real estate yang terdaftar di ISSI periode 2013 - 2015, maka dapat disimpulkan pada penelitian ini adalah :

1. Variabel eksogen Return on Equity (ROE), Earning per Share (EPS), dan Debt to Equity Ratio (DER) secara parsial masing - masing variabel terdapat pengaruh sebagai berikut :

a. Return on Equity (ROE) tidak berpengaruh signifikan terhadap return saham perusahaan property dan real estate yang terdaftar di Indeks Saham Syariah Indonesia (ISSI). ROE dengan return saham memiliki hubungan positif, sehingga jika ROE mengalami kenaikan satu unit nilai maka return saham akan naik sebesar 1,219552 unit.

b. Earning Per Share (EPS) berpengaruh signifikan terhadap return saham perusahaan property dan real estate yang terdaftar di Indeks Saham Syariah Indonesia (ISSI). EPS dengan return saham memiliki hubungan positif, sehingga jika EPS mengalami kenaikan satu unit nilai maka return saham akan naik sebesar 0,001027 unit.

c. Debt to Equity Ratio (DER) berpengaruh signifikan terhadap return saham perusahaan property dan real estate yang terdaftar di Indeks Saham SyariahIndonesia (ISSI). DER dengan return saham memiliki hubungan positif, sehingga jika DER mengalami kenaikan satu unit nilai maka return saham akan naik sebesar 0,790385 unit.

2. Variabel Return on Equity (ROE), Earning Per Share (EPS) dan Debt to Equty Ratio (DER) berpengaruh signifikan secara simultan terhadap return saham pada perusahaan property dan real estate yang terdaftar di ISSI tahun 2013 - 2015. Hasil R-squared sebesar 17,6\%, sedangkan sisanya sebesar $82,4 \%$ adalah variabel lain yang belum masuk dalam model.

\section{DAFTAR PUSTAKA}

Ajija, dan Shochrul Rohmatul. 2011. Cara Cerdas Menguasai Eviews. Jakarta : Salemba Empat.

Anshori, Muslich dan Sri Iswati. 2009. Buku Ajar Metodelogi Penelitian Kuantitatif. Surabaya : Airlangga Universitas Press.

Ansofino, dkk. 2016. Buku Ajar Ekonometrika. Yogyakarta : Deepublish. 
Latifah, et al/Jurnal Ekonomi Syariah Teori dan Terapan Vol. 4 No. 12 Desember 2017: 1009-1023; PENGARUH RETURN ON EQUITY, EARNING PER SHARE, DAN DEBT TO EQUITY RATIO TERHADAP RETURN SAHAM (STUDI PADA EMITEN SAHAM SYARIAH SEKTOR PROPERTY DAN REAL ESTATE YANG TERDAFTAR DI ISSI TAHUN (2013 - 2015)

Ariefianto, Moch. Doddy. 2012. Ekonometrika Esensi dan Aplikasi dengan Menggunakan Eviews. Jakarta : Erlangga.

Azis, Musdalifah, Sri Mintari dan Maryam Nadir. 2015. Manajemen Investasi: Fundamental, Teknikal, Perilaku Investor dan Return Saham. Yogyakarta : Deepublish.

Baroroh, Ali. 2008. Trik - trik Analisis Statistik dengan SPSS15. Jakarta: PT Elex Media Komputindo.

Brigham, Eugene F dan Joel F. Houston. 2001. Manajemen Keuangan Edisi Kedelapan Buku 1. Jakarta: Salemba Empat.

2010. Dasar - dasar Manajemen Keuangan Edisi 11 Buku 1. Jakarta : Salemba Empat.

Bukhari, Imam. 2016. Kitab Hadits Shahih Bukhari: 4000 Hadits dengan Total 7.7275 Hadist Shahih Referensi Umat Islam. Jakarta: Shahih.

Darmaji, Ciptano dan Hendy $M$. Fakhruddin. 2001. Pasar Modal Indonesia Pendekatan Tanya Jawab. Jakarta: Salemba Empat.

Daruyudhasena, Dian. 2013. Pengaruh Current Ratio (CR) dan Net Profit Margin (NPM) terhadap return saham syariah (Studi pada perusahaan pertambangan yang terdafatar dalam Jll tahun 2008 - 2012). Disertai tidak diterbitkan. Fakultas Ekonomi dan Bisnis Universitas Airlangga Surabaya.

Dewi, Rizky Aprilian Kusuma. 2016. Pengaruh Debt to Asset Ratio dan Perputaran Persediaan Terhadap Profitabilitas Perusahaan Tekstil dan Garment yang Terdaftar Pada ISSI Periode 2012 - September 2015. Disertai tidak diterbitkan. Fakultas Ekonomi dan Bisnis Universitas Airlangga Surabaya.

Effendi, Nury dan Maman Setiawan. 2014. Ekonometrika Pendekatan Teori dan Terapan. Jakarta : Salemba Empat.

Fakhruddin, Hendy M. 2008. Tanya Jawab Pasar Modal untuk SMA. Jakarta : PT Elex Media Komputindo.
Fakhruddin, Hendy M. 2008. Go Public: Strategi Pendanaan dan Peningkatan Nilai Perusahaan. Jakarta : PT Elex Media Komputindo.

Ganto, dkk. 2008. Pengaruh Kinerja Keuangan Perusahaan Manufaktur terhadap Return Saham di Bursa Efek Indonesia. Jurnal Media Riset Akuntansi, Auditting dan Informasi, (Online), Jilid 8, No. 1, (unimal.ac.id, diakses 14 Januari 2017)

Ghazaly, Abdul Rahman, Ghufron Ihsan, dan Sapiudin Shidiq. 2010. Fiqh Muamalat. Jakarta : Prenada Media Group.

Gujarati, Damodar N. dan Dawn C. Porter. 2013. Dasar - dasar Ekonometrika Edisi 5. Jakarta: Salemba Empat.

Hamdi, Asep Saepul. 2014. Metode Penelitian Kuantitatif Aplikasi dalam Pendidikan. Yogyakarta : Deepublish.

Hidayat, Taufik. 2011. Buku Pintar Investasi Syariah. Jakarta : PT TransMedia.

2013. Membuat Aplikasi Excel untuk UKM. Jakarta : Mediakita.

Huda, Nurul dan Mustafa Edwin Nasution. 2007. Investasi pada Pasar Modal Syariah. Jakarta : Prenada Media Group.

Husnan, Suad. 2009. Dasar - dasar Teori Portofolio dan Analisis Sekuritas Edisi Keempat. Yogyakarta: LPP STIM YKPN.

Jaya, Ade Kemala dan Tita Mandela. 2015. Pengaruh Kinerja Keuangan terhadap Return Saham pada Perusahaan Pertambangan yang Terdaftar di Bursa Efek Indonesia. Jurnal Akuisis, (Online), Jilid 11, No. 2, (jurnal.binadarma.ac.id, diakses 25 Desember 2016).

Jogiyanto. 2010. Teori Portofolio dan Analisis Investasi Edisi ketujuh. Yogyakarta : BPFE

Kasmir. 2015. Analisis Laporan Kevangan. Jakarta : PT Raja Grafindo Persada.

Kweon, Arthur J, John D. Martin, J. William Petty, dan David F.Scott, JR. 1999. Dasar - dasar Manajemen Keuangan Edisi Ketujuh. Jakarta : Salemba Empat. 
Latifah, et al/Jurnal Ekonomi Syariah Teori dan Terapan Vol. 4 No. 12 Desember 2017: 1009-1023; PENGARUH RETURN ON EQUITY, EARNING PER SHARE, DAN DEBT TO EQUITY RATIO TERHADAP RETURN SAHAM (STUDI PADA EMITEN SAHAM SYARIAH SEKTOR PROPERTY DAN REAL ESTATE YANG TERDAFTAR DI ISSI TAHUN (2013 - 2015)

Muhammad. 2011 . Manajemen Keuangan Syariah : Analisis Figh dan Kevangan. Yogyakarta: UUP STIM YKPN.

Muliani, Linda. 2013. Analisis Pengaruh Return On Equity (ROE) dan Economic Value Added (EVA) terhadap Return Saham Perusahaan Manufaktur yang Terdaftar di Bursa Efek Indonesia. Disertai diterbitkan. Fakultas Ekonomi Universitas Esa Unggul Jakarta.

Mulyadi. 2007. Sistem Perencanaan dan Pengendalian Manajemen. Jakarta : Salemba Empat.

Nuryana, Ida. 2013. Pengaruh Rasio Keuangan terhadap Return Saham Perusahaan LQ45 di Bursa Efek Jakarta. Jurnal Akuntansi Aktual, (Online), Jilid 2, No. 2, (um.ac.id, diakses 14 Januari 2017)

Rochaety, Eti dan Ratih Tresnati. 2013. Kamus Istilah Ekonomi. Jakarta: PT Bumi Aksara.

Roslianti, Rizkary. 2014. Pengaruh Kinerja Kevangan terhadap Return Saham (Studi Pada Emiten Saham Syariah Sektor Manufaktur yang Terdaftar di Indeks Saham Syariah Indonesia Tahun 2011 - 2012). Disertai tidak diterbitkan. Fakultas Ekonomi dan Bisnis Universitas Airlangga Surabaya.

Samsul, Mohamad. 2006. Pasar Modal dan Manajemen Portofolio. Surabaya : Erlangga.

Sari, Luvy Nurfinda dan Lintang Venusita. 2013. Pengaruh Kinerja Keuangan terhadap Return Saham Perusahaan Property dan Real Estate. Jurnal IImu Manajemen, (Online), Jilid 1, No. 3, (ejournal.unesa.ac.id, diakses 13 November 2016).

Sharpe, William F, Gordon J. Alexander, dan Jeffery V. Bailey. 1997. Investasi Jilid 2. Jakarta: Pretice-Hall Inc.

Shihab, M. Quraish. 2002. Tafsir Al Mishbah : pesan, kesan dan keserasian Al Qur'an. Jakarta : Lentera Hati.

Siagin, Dergibson dan Sugiarto. 2000. Metode Statistika untuk Bisnis dan Ekonomi. Jakarta : PT Gramedia Puataka Umum.
Sudana, I Made. 2015. Manajemen Keuangan Perusahaan Teori dan Praktik Edisi 2. Jakarta: Erlangga.

Sugiarto, Agung. 2011. Analisa Pengaruh Beta, Size Perusahaan, DER dan PBV Ratio terhadap Return Saham. Jurnal Dinamika Akuntansi, (Online), Jilid 3, No. 1, (http://journal.unnes.ac.id, diakses 13 November 2016).

Sugiono, Arief. 2008. Manajemen Keuangan untuk Praktisi Keuangan. Jakarta : Grasindo.

Sugiono, Arief dan Edy Untung. 2008. Panduan Praktis Dasar Analisa Laporan Kevangan Pengatahuan Dasar bagi Mahasiswa dan Praktisi Perbankan. Jakarta : Grasindo.

Sugiono, Arief, Yanuar Nanok Soenarno, dan Synthia Madya Kusumawati. 2009. Akuntansi dan Pelaporan Kuangan untuk Bisnis Skala Kecil dan Menengah. Jakarta : Grasindo.

Sula, Muhammad Syakir. 2004. Asuransi Syariah (Life and General): Konsep dan Sistem Operasional. Jakarta : Gema Insani.

Sunardi, Harjono. 2010. Pengaruh Penilaian Kinerja dengan ROI dan EVA terhadap Return Saham pada Perusahaan yang Tergabung dalam Indeks LQ45 di Bursa Efek Indonesia. Jurnal Akuntansi, (Online), Jilid 2, No. 1, (www.maranatha.edu, diakses 23 Oktober 2016).

Susilo, Bambang. 2009. Pasar Modal Mekanisme Perdagangan Saham, Analisis Sekuritas, dan Strategi Investasi di BEI. Yogyakarta : UPP STIM YKPN.

Susilowati, Yeye. 2011. Reaksi Signal Rasio Profitabilitas dan Rasio Solvabilitas terhadap Return Saham Perusahaan. Jurnal Dinamika Keuangan dan Perbankan, (Online), Jilid 3, No. 1, unisbank.ac.id, diakses 14 Januari 2017)

Sutedi, Adrian. 2011. Pasar Modal Syariah: Sarana Investasi Kevangan berdasarkan Prinsip Syariah. Jakarta : Sinar Grafika. 
Syahputri, Rianti. 2015. Pengaruh Return On Asset dan Net Profit Margin serta Earning Per Share (EPS) terhadap Return Saham pada Emiten Jakarta Islamic Index Tahun 2010 - 2013. Disertai tidak diterbitkan. Fakultas Ekonomi dan Bisnis Universitas Airlangga Surabaya.

Tambunan, Andy Porman. 2007. Menilai Harga Wajar Saham (Stock Valuation). Jakarta : PT Elex Media Komputindo.

Tendellin, Eduardus. 2010. Portofolio dan Investasi Teori dan Aplikasi. Yogyakarta : Kanisius.

Wijaya, David. 2008. Pengaruh Rasio Modal Saham terhadap Return Saham Perusahaan - perusahaan Telekomunikasi Go Public di Indonesia Periode 2007. Jurnal Managemen dan Kewirausahaan, (Online), Jilid 10, No. 2 , (jurnalmanajemen.petra.ac.id, diakses 14 Januari 2017)

Zuliarni, Sri. 2012. Pengaruh Kinerja Kevangan Terhadap Harga Saham Pada Perusahaan Mining and Mining Service di Bursa Efek Indonesia (BEI). Jurnal Aplikasi Bisnis, (Online), Jilid 3, No. 1. (www.ejournal.unri.ac.id, diakses 13 Novomber 2016).

www.idx.co.iddiakses 17 Oktober 2016 pukul 14:16

www.tradingeconomics.com/indonesia/h ousing-index diakses 31 Oktober 2016 pukul 22:01. 